\title{
Overnight continuous saline irrigation after transurethral resection for non-muscle-invasive bladder cancer is helpful in prevention of early recurrence
}

Jungmo Do; Sin Woo Lee; Seong Uk Jeh; Jeong Seok Hwa; Jae Seog Hyun; See Min Choi Department of Urology, Gyeongsang National University Hospital, Jinju, Korea

Acknowledgement: Abstract was presented as a poster at the 2018 AUA Annual Congress, May 18-21, San Francisco, CA. Poster \# MP08-20.

Cite as: Can Urol Assoc J 2018 June 8; Epub ahead of print. http://dx.doi.org/10.5489/cuaj.5122

Published online June 8, 2018

\section{Abstract}

Introduction: It has been reported that many methods prevent recurrence after transurethral resection of bladder tumour (TURB) for non-muscle-invasive bladder cancer (NMIBC), but it has rarely been reported that overnight continuous saline irrigation is effective in preventing recurrence. The purpose of this study was to evaluate the efficacy of overnight continuous saline irrigation in preventing recurrence after TURB.

Methods: We retrospectively studied patients with NMIBC who underwent TURB from January 2010 to May 2015 at our institution. Patients who underwent cystoscopy every 12 weeks during the first year after surgery were included. Patients with pT2 $\geq$, lymph node metastasis, or distant metastasis were excluded. The overnight continuous saline irrigation (OCSI) group and the no irrigation group were compared and analyzed.

Results: A total of 332 patients were included in the study. There were no differences in the basic characteristics of the patients between the two groups. In the OCSI group, the recurrence-free survival rate was higher than that in the no irrigation group, indicating that there was a significant difference between the two groups $(\mathrm{p}=0.032)$.

Conclusions: After TURB surgery, OCSI may help prevent early recurrence of NMIBC. 


\section{Introduction}

Approximately $70 \%$ of bladder cancers present as non-muscle invasive bladder cancer (NMIBC). ${ }^{1}$ Transurethral resection (TUR) still remains the gold standard for the treatment of NMIBC. However, even if TUR completely removes tumors of Ta and T1 stages, $40 \%$ recur within 1 year. ${ }^{2,3}$ Therefore, intravesical chemotherapy or Bacillus Calmette Guérin (BCG) immunotherapy is recommended after TUR for prevention of recurrence and progression of high risk NMIBC. ${ }^{4,5}$ However, intravesical chemotherapy and BCG immunotherapy have local or systemic side effects and they are difficult to apply in all patients. In addition, intravesical chemotherapy may have a problem of high cost due to the chemotherapeutic agent, proficiency of medical personnel dealing with the chemotherapeutic agent, and serious complications due to the chemotherapeutic agent if bladder perforation is suspected after surgery. ${ }^{6,7}$ Furthermore, BCG immunotherapy is problematic in terms of smooth supply and demand due to global shortage. ${ }^{8}$

According to Soloway et al. ${ }^{9}$, one of the mechanisms of bladder tumor recurrence is implantation of floating tumor cells in the bladder wall after transurethral resection of bladder tumor (TURB). Therefore, we think that it is possible to prevent early recurrence by removing tumor cells floating in the bladder and preventing implantation in the bladder wall by performing overnight continuous saline irrigation (OCSI) after TUR. We compared the OCSI group and the no irrigation group after TUR to determine whether this technique was effective in preventing early recurrence.

\section{Methods}

\section{Subjects}

We retrospectively reviewed patients who were diagnosed with NMIBC after TUR at our hospital from January 2010 to May 2015 and who had been followed up for 12 months postoperatively. In our hospital, since 2014, all TUR patients have undergone OCSI. Patients who had pT2 $\geq$, lymph node metastasis, or distant metastasis on computed tomography images after TUR as well as who underwent mitomycin-C (MMC) or epirubicin instillation after TUR, or repeated TUR were excluded.

\section{Followup}

Patients underwent cystoscopy every 12 weeks \pm 2 weeks during follow-up and they were followed up for 12 months. Recurrence of bladder cancer was confirmed by cystoscopy.

\section{Comparison method}

TUR was performed for removing the tumors completely, and a 22Fr 3-way Foley catheter was inserted and continuous irrigation was started by connecting a $3000 \mathrm{cc}$ bag of normal saline to the Foley catheter in the OCSI group (using a total of 9000 cc of saline). But, after TUR was performed, a 16Fr Foley catheter was inserted and drainage was performed in the no irrigation group. The baseline characteristics and the recurrence-free survival rate of the OCSI group and the no irrigation group were compared. 


\section{Statistical analysis}

The standard chi-square test was used to compare the two groups and the recurrence-free survival rate was calculated by the Kaplan-Meier method with log-rank test. The statistical program used was SPSS version 21.0 for Windows. A $P$ value $<0.05$ was considered statistically significant.

\section{Results}

A total of 332 patients were included in the study. The no irrigation group included 212 patients and the OCSI group included 120 patients. No significant differences were seen between the groups in term of age, gender, hypertension, diabetes, stage, tumor grade, tumor size, number of tumors, BCG immunotherapy. Regarding smoking, which is known as a very important risk factor, no significant differences were also seen between groups of patients who are on smoking, who do not smoke, and who quit smoking for more than one year (Table $1)$.

To evaluate the treatment efficacy of OCSI, the duration of time to the initial recurrence, frequency of recurrence, recurrence-free survival rate in the OCSI group were compared to no irrigation group.

The mean duration of time to the initial recurrence in the no irrigation group was $277.19 \pm 7.39$ days (95\% CI 262.70-291.68) and that in the OCSI group was $302.85 \pm 8.11$ days (95\% CI 286.96-318.74). In non-irrigation group, 131 patients (61.8\%) had no recurrence while 81 patients (38.2\%) had recurrence. In OCSI group, however, 88 patients (73.3\%) had no recurrence while 32 patients (26.4\%) had recurrence.

The recurrence-free survival rate at 12 months after surgery was significantly higher in the OCSI group than in the no irrigation group (log-rank test $P=0.032$ ) (Figure 1).

\section{Discussion}

Recurrence of bladder cancer after TUR surgery may be caused by residual cancer due to incomplete resection, failure to identify a small lesion, and new implantation of floating tumor cells. ${ }^{10}$ These cancer recurrence mechanisms can be blocked to prevent recurrence. The existing BCG instillation destroys floating cancer cells, and intravesical chemotherapy is known to remove residual cancer cells at the resection site. ${ }^{4,11}$ However, intravesical chemotherapy is not completely safe for the patients. In some case studies, patients died due to successive complications caused by MMC and epirubicin instillation. ${ }^{12-14}$ BCG immunotherapy has also been reported in patients who died of mild complications to severe complications. ${ }^{15-19}$

For those reasons, use of intravesical chemotherapy after TURB in NMIBC is on the decline among urologists. According to the studies, 18\% of European urologists responded that they always choose intravesical chemotherapy while $28 \%$ responded that they never use it. Among American urologists, 2\% always performed intravesical chemotherapy while $66 \%$ never chose to perform. ${ }^{6,7}$

One study showed that osmotic cytolysis by irrigation with sterile water can be used to destroy tumor cells ${ }^{20}$, and another study suggested sterile water irrigation after TUR 
surgery as an alternative to intravesical chemotherapy. ${ }^{21}$ However, there are reports suggesting that distilled water can cause electrolyte imbalance and serious complications such as intravascular hemolysis and death. ${ }^{22,23}$

In rectal cancer, the main cause of local recurrence after curative operation has been found to be implantation of viable shed cancer cells. Local recurrence did not occur when saline irrigation was performed 20 times with a $30 \mathrm{ml}$ enema syringe before anastomosis of the remnant rectum, but recurrence was observed in $11 \%$ of patients without irrigation. ${ }^{24}$ In another rectal cancer meta-analysis study, normal saline wash out showed better reduction in local recurrence than cetrimide, povidone-iodine, and formalin solution wash out and irrigation volume of $1500 \mathrm{~mL}$ had better results than volume of less than $1500 \mathrm{~mL}$, indicating efficacy of saline irrigation. ${ }^{25}$

Originally, the purpose of physiological saline perfusion was to achieve hemostasis and clot removal in bladder hemorrhage. However, the authors speculated that continuous saline irrigation after TUR surgery could safely reduce the recurrence rate compared to the other methods if it can remove floating tumor cells and prevent implantation in the bladder wall although continuous saline irrigation cannot destroy cancer cells or remove residual cancer cells.

Onishi et al. ${ }^{26}$ stated that recurrence-free rates at 1,3 , and 5 years were $76.7 \%, 67.3 \%$, and $61.3 \%$, respectively, in the continuous saline irrigation group $(\mathrm{n}=123)$ and $81 \%, 58 \%$ and 58\%, respectively, in the MMC instillation group $(n=115)$, indicating that there was no significant difference between the two groups. Thus, the study insisted that saline irrigation is not inferior to MMC in terms of efficacy in reducing recurrence in bladder cancer. In a recently published study, Onishi et al. ${ }^{27}$ reconfirmed that there was no significant difference in the 5-year recurrence-free rates of 62.6\% and 70.4\% (log-rank test $P=0.53$ ) between the continuous saline irrigation group $(\mathrm{n}=114)$ and the MMC instillation group $(\mathrm{n}=$ 113) through a randomized controlled trial.

In this study, we assessed the effects of continuous saline irrigation in the OCSI group and compared this group with the no irrigation group, and the results showed that continuous saline irrigation was effective in preventing early recurrence.

This study was performed at a single institution, the number of patients included was small, and the follow-up period was short; therefore, only early recurrence was observed up to 1 year after surgery, and there was a limitation that it was performed retrospectively. It is suggested that prospective, multicenter, long-term follow-up studies with more patients are needed in the future.

\section{Conclusion}

After TURB surgery, OCSI could reduce early recurrence of NMIBC. OCSI is expected to be more widely used because it is an economical, safe and easy to perform technique. 


\section{References}

1. Isharwal S, Konety B. Non-muscle invasive bladder cancer risk stratification. Indian J Urol. 2015;31(4):289-296.

2. Oosterlinck W, Lobel B, Jakse G, et al. Guidelines on bladder cancer. Eur Urol. 2002;41(2):105-112.

3. Witjes JA. Topic issue on new treatments in bladder cancer. World J Urol. 2009;27(3):285-287.

4. Sylvester RJ, Oosterlinck W, van der Meijden AP. A single immediate postoperative instillation of chemotherapy decreases the risk of recurrence in patients with stage Ta T1 bladder cancer: a meta-analysis of published results of randomized clinical trials. J Urol. 2004;171(6 Pt 1):2186-2190, quiz 2435.

5. Brausi M, Witjes JA, Lamm D, et al. A review of current guidelines and best practice recommendations for the management of nonmuscle invasive bladder cancer by the International Bladder Cancer Group. J Urol. 2011;186(6):2158-2167.

6. Cookson MS, Chang SS, Oefelein MG, Gallagher JR, Schwartz B, Heap K. National practice patterns for immediate postoperative instillation of chemotherapy in nonmuscle invasive bladder cancer. J Urol. 2012;187(5):1571-1576.

7. Palou-Redorta J, Roupret M, Gallagher JR, Heap K, Corbell C, Schwartz B. The use of immediate postoperative instillations of intravesical chemotherapy after TURBT of NMIBC among European countries. World J Urol. 2014;32(2):525-530.

8. Fernandez-Gomez JM, Carballido-Rodriguez J, Cozar-Olmo JM, et al. Treatment of non muscle invasive bladder tumor related to the problem of bacillus Calmette-Guerin availability. Consensus of a Spanish expert's panel. Spanish Association of Urology. Actas Urol Esp. 2013;37(7):387-394.

9. Soloway MS, Masters S. Urothelial susceptibility to tumor cell implantation: influence of cauterization. Cancer. 1980;46(5):1158-1163.

10. Brausi M, Collette L, Kurth K, et al. Variability in the recurrence rate at first follow-up cystoscopy after TUR in stage Ta T1 transitional cell carcinoma of the bladder: a combined analysis of seven EORTC studies. Eur Urol. 2002;41(5):523-531.

11. Iida K, Naiki T, Kawai N, et al. Bacillus Calmette-Guerin therapy after the second transurethral resection significantly decreases recurrence in patients with new onset highgrade T1 bladder cancer. BMC Urol. 2016;16:8.

12. Cliff AM, Romaniuk CS, Parr NJ. Perivesical inflammation after early mitomycin $C$ instillation. BJU Int. 2000;85(4):556-557.

13. Oddens JR, van der Meijden AP, Sylvester R. One immediate postoperative instillation of chemotherapy in low risk Ta, T1 bladder cancer patients. Is it always safe? Eur Urol. 2004;46(3):336-338.

14. Nieuwenhuijzen JA, Bex A, Horenblas S. Unusual complication after immediate postoperative intravesical mitomycin C instillation. Eur Urol. 2003;43(6):711-712.

15. Singh NP, Prakash A, Kubba S, et al. Nephrotic syndrome as a complication of intravesical BCG treatment of transitional cell carcinoma of urinary bladder. Ren Fail. 
2007;29(2):227-229.

16. Korac M, Milosevic B, Lavadinovic L, Janjic A, Brmbolic B. [Disseminated BCG infection in patients with urinary bladder carcinoma]. Med Pregl. 2009;62(11-12):592595.

17. Rogozinski P, Taracha-Guz D, Pecikiewicz P, et al. [Granulomatous pneumonia as a complication of intravesical BCG immunotherapy--a case report]. Pneumonol Alergol Pol. 2014;82(2):163-169.

18. Ye HY, Xu QQ, Huang XB, Ma K, Wang XF. [Tuberculous prostatic abscess following intravesical bacillus Calmette-Guerin immunotherapy: a case report]. Beijing Da Xue Хие Bao. 2015;47(6):1039-1041.

19. Floros N, Meletiadis K, Kusenack U, et al. Ruptured Mycotic Aortic Aneurysm after Bacille Calmette-Guerin Therapy. Ann Vasc Surg. 2015;29(7):1450 e1451-1454.

20. Fechner G, Pocha K, Schmidt D, Muller SC. Reducing recurrence and costs in superficial bladder cancer: preclinical evaluation of osmotic cytolysis by distilled water vs. mitomycin. Int J Clin Pract. 2006;60(10):1178-1180.

21. Bijalwan P, Pooleri GK, Thomas A. Comparison of sterile water irrigation versus intravesical mitomycin $\mathrm{C}$ in preventing recurrence of nonmuscle invasive bladder cancer after transurethral resection. Indian J Urol. 2017;33(2):144-148.

22. Bell MD. Sudden death due to intravascular hemolysis after bladder irrigation with distilled water. J Forensic Sci. 1992;37(5):1401-1406.

23. Dorotta I, Basali A, Ritchey M, O'Hara JF, Jr., Sprung J. Transurethral resection syndrome after bladder perforation. Anesth Analg. 2003;97(5):1536-1538.

24. Fukuda I, Kameyama M, Imaoka S, et al. [Prevention of local recurrence after sphinctersaving resection for rectal cancer]. Gan To Kagaku Ryoho. 1991;18(11):1965-1967.

25. Zhou C, Ren Y, Li J, et al. Association between irrigation fluids, washout volumes and risk of local recurrence of anterior resection for rectal cancer: a meta-analysis of 427 cases and 492 controls. PLoS One. 2014;9(5):e95699.

26. Onishi T, Sasaki T, Hoshina A, Yabana T. Continuous saline bladder irrigation after transurethral resection is a prophylactic treatment choice for non-muscle invasive bladder tumor. Anticancer Res. 2011;31(4):1471-1474.

27. Onishi T, Sugino Y, Shibahara T, Masui S, Yabana T, Sasaki T. Randomized controlled study of the efficacy and safety of continuous saline bladder irrigation after transurethral resection for the treatment of non-muscle-invasive bladder cancer. BJU Int.

2017;119(2):276-282. 
Figures and Tables

Fig. 1. Recurrence-free survival rate in the overnight continuous saline irrigation group and the no irrigation group. TURB: transurethral resection of bladder tumour.

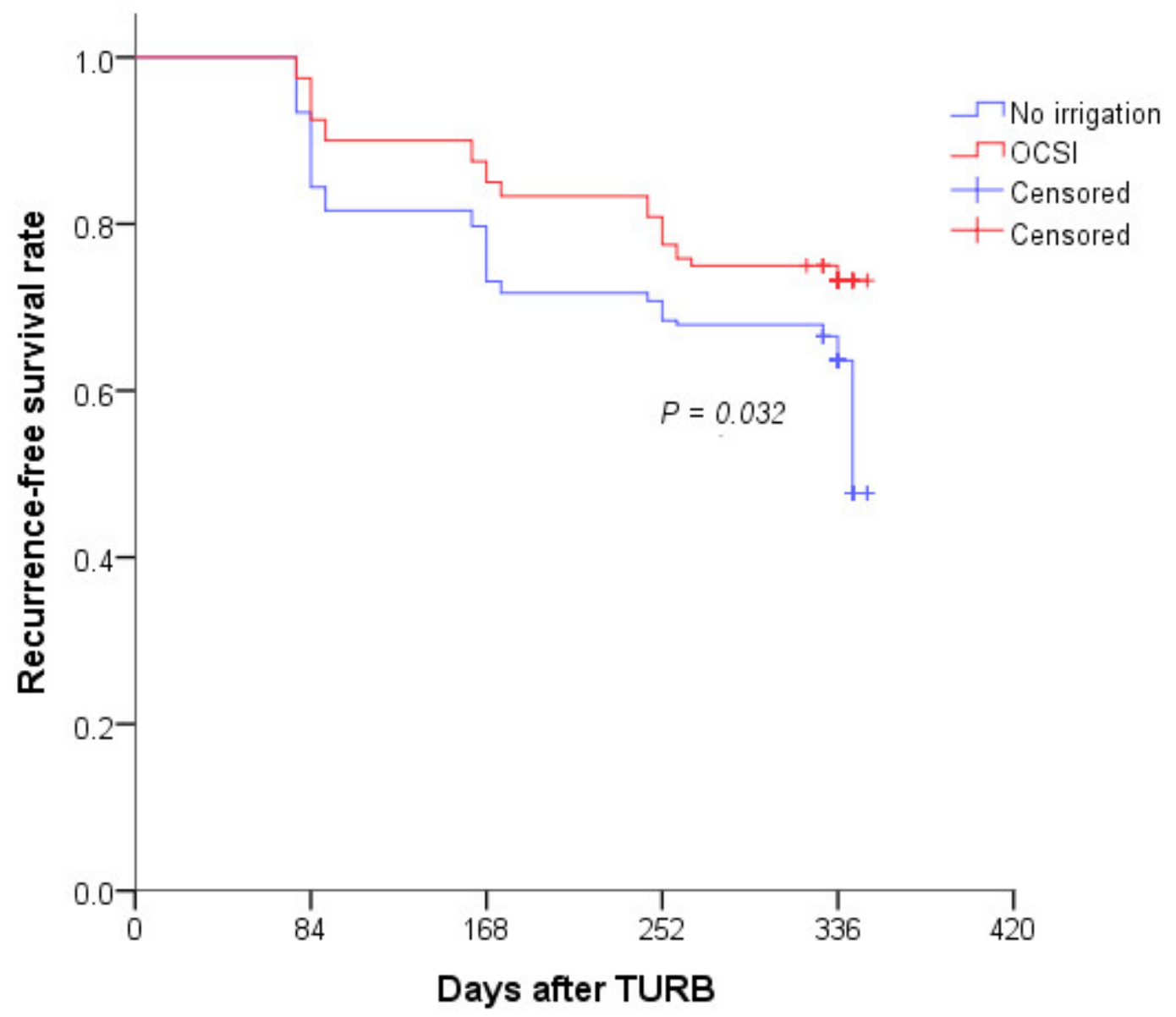




\begin{tabular}{|c|c|c|c|}
\hline & $\begin{array}{l}\text { No irrigation group } \\
\qquad(\mathrm{n}=212)\end{array}$ & $\begin{array}{l}\text { OCSI group } \\
(n=120)\end{array}$ & $\mathrm{p}$ \\
\hline Age & $66.80 \pm 12.28$ & $67.56 \pm 12.14$ & 0.586 \\
\hline $\begin{array}{l}\text { Gender } \\
\text { Male } \\
\text { Female }\end{array}$ & $\begin{array}{c}178(84.0 \%) \\
34(16.0 \%)\end{array}$ & $\begin{array}{c}100(83.3 \%) \\
20(16.7 \%)\end{array}$ & 0.881 \\
\hline $\begin{array}{l}\text { Hypertension } \\
\text { Yes } \\
\text { No }\end{array}$ & $\begin{array}{c}56(26.4 \%) \\
156(73.6 \%)\end{array}$ & $\begin{array}{l}28(23.3 \%) \\
92(76.7 \%)\end{array}$ & 0.535 \\
\hline $\begin{array}{l}\text { Diabetes } \\
\text { Yes } \\
\text { No }\end{array}$ & $\begin{array}{c}28(13.2 \%) \\
184(86.8 \%)\end{array}$ & $\begin{array}{c}18(15.0 \%) \\
102(85.0 \%)\end{array}$ & 0.650 \\
\hline $\begin{array}{l}\text { Smoking history } \\
\text { Yes } \\
\text { No } \\
\text { Cessation (>1yr) }\end{array}$ & $\begin{array}{l}81(38.2 \%) \\
59(27.8 \%) \\
72(34.0 \%) \\
\end{array}$ & $\begin{array}{l}43(35.8 \%) \\
32(26.7 \%) \\
45(37.5 \%) \\
\end{array}$ & 0.468 \\
\hline $\begin{array}{l}\text { T stage } \\
\text { Ta } \\
\text { T1 } \\
\text { CIS }\end{array}$ & $\begin{array}{c}141(66.5 \%) \\
58(27.4 \%) \\
13(6.1 \%) \\
\end{array}$ & $\begin{array}{c}68(56.7 \%) \\
42(35.0 \%) \\
10(8.3 \%) \\
\end{array}$ & 0.202 \\
\hline $\begin{array}{l}\text { Grade } \\
\text { PUNLMP } \\
\text { Low-grade } \\
\text { High-grade } \\
\end{array}$ & $\begin{array}{c}29(13.7 \%) \\
126(59.4 \%) \\
57(26.9 \%) \\
\end{array}$ & $\begin{array}{l}18(15.0 \%) \\
73(60.8 \%) \\
29(24.2 \%) \\
\end{array}$ & 0.573 \\
\hline $\begin{array}{l}\text { Size } \\
<3 \mathrm{~cm} \\
\geq 3 \mathrm{~cm} \\
\end{array}$ & $\begin{array}{c}174(82.1 \%) \\
38(17.9 \%) \\
\end{array}$ & $\begin{array}{c}104(86.7 \%) \\
16(13.3 \%) \\
\end{array}$ & 0.276 \\
\hline $\begin{array}{l}\text { Multiplicity } \\
\text { Single } \\
\text { Multiple } \\
\end{array}$ & $\begin{array}{c}149(70.3 \%) \\
63(29.7 \%) \\
\end{array}$ & $\begin{array}{l}77(64.2 \%) \\
43(35.8 \%) \\
\end{array}$ & 0.251 \\
\hline $\begin{array}{l}\text { BCG } \\
\text { Yes } \\
\text { No } \\
\end{array}$ & $\begin{array}{c}97(45.8 \%) \\
115(54.2 \%) \\
\end{array}$ & $\begin{array}{l}62(51.7 \%) \\
58(48.3 \%)\end{array}$ & 0.300 \\
\hline
\end{tabular}

Values are presented as mean \pm standard deviation for continuous variables and number for categorical variables. BCG, Bacillus Calmette-Guerin; PUNLMP: Papillary urothelial neoplasm of low malignant potential; 